Pesquisa em Foco ISSN (2176-0136)

http://ppg.revistas.uema.br/index.php/PESQUISA EM FOCO

São Luís, v. 22, n. 2, Jul./Dez. 2017

EDUCAÇÃO E EMANCIPAÇÃO

\author{
Rafael Rossi ${ }^{1}$
}

\title{
RESUMO
}

O presente artigo representa um esforço teórico de compreensão da relação que se estabelece entre o complexo social da educação e a categoria fundante do ser social: o trabalho. Nesse aspecto, partimos das elaborações oferecidas pela ontologia marxiana por ajudar a compreender a realidade objetiva com base em seu próprio movimento histórico de complexificação. Esta discussão é fundamental para analisar os limites e as possibilidades da prática educativa perante a sociabilidade capitalista da contemporaneidade. Com efeito, tratamos desta temática a partir das bases ontometodológicas oferecidas por Marx, Lukács, Mészáros, S. Lessa e I. Tonet; pois estes autores, dentre outros, oferecem reflexões de ordem eminentemente crítica e radical à reflexão ideopolítica sobre o complexo educacional.

Palavras-chave: Ontologia Marxiana; Trabalho; Educação; Emancipação.

\section{EDUCATION AND EMANCIPATION}

\begin{abstract}
This paper presents a theoretical understanding of effort of the relationship that is established between the social complex of education and basic category of social being: work. In this respect, we set the elaborations offered by marxian ontology for helping to understand the objective reality based on their own historical movement of complexity. This discussion is critical to analyze the limits and possibilities of educational practice before the capitalist sociability of contemporaneity. Indeed, we treat this issue from the

\footnotetext{
${ }^{1}$ Doutor em Educação (UNESP). Professor Adjunto na Universidade Federal de Mato Grosso, Campo Grande - MS. E-mail: rafaelrossi6789@hotmail.com
} 
onto-methodological bases offered by Marx, Lukács, Mészáros, S. Lessa and I. Tonet; as these authors, among others, offer highly critical order reflections and the radical ideopolitics reflection on the educational complex.

Keywords: Marxian Ontology; Work; Education; Emancipation.

\section{INTRODUÇÃO}

É muito comum na discussão acadêmica e/ou política atribuir à educação tarefas hercúleas como: dar conta das desigualdades sociais, promover a construção de uma "cidadania crítica", ser "humanizadora" e vários outros rótulos imagináveis. Há também outra perspectiva, ou seja, existem posturas que desvalorizam a educação e acreditam que ela nada pode no tocante à transformação social. Na contramão destas duas linhas de raciocínio, entendemos que o correto equacionamento da educação passa pelo entendimento - a partir da ontologia marxiana - da sua dependência ontológica, autonomia relativa e determinação recíproca para com o trabalho.

Trataremos - brevemente - destes aspectos na primeira parte do texto para que em seguida possamos compreender a impossibilidade real objetiva de uma "educação emancipadora" no âmbito da sociabilidade burguesa e, ao mesmo tempo, as possibilidades reais que ela pode oferecer. Com efeito, é preciso explicitar as contradições estruturais e irreformáveis do sistema do capital, num segundo momento do texto, para que se possa desenvolver uma reflexão capaz de apreender os limites e as potencialidades do complexo social da educação. Deste modo, poderemos avançar para a explicitação das formulações elaboradas por I. Tonet (2005; 2007; 2010; 2012; 2014) no que se refere ao desenvolvimento de atividades educativas de caráter emancipador enquanto reflexões imprescindíveis para a crítica radical contra o capital.

Nosso objetivo mais geral é compreender o complexo social da educação por meio das análises oriundas da ontologia marxiana em sua relação com a categoria fundante do

Pesquisa em Foco, São Luís, vol. 22, n. 2, p. 31-62. Jul./Dez. 2017 


\section{Pesquisa em Foco ISSN (2176-0136)}

http://ppg.revistas.uema.br/index.php/PESQUISA EM FOCO

São Luís, v. 22, n. 2, Jul./Dez. 2017

ser social que é o trabalho e, assim, contribuirmos com uma reflexão de ordem revolucionária na discussão educacional em tempos nossos de crise estrutural do capital.

\section{TRABALHO E EDUCAÇÃO: UMA RELAÇÃO ONTOLÓGICA}

Realizando uma síntese muito grande, podemos dizer que o ser humano não é "dado" por natureza, isto é, não se forma por aspectos meramente biológicos e/ou naturais tão somente. $\mathrm{O}$ indivíduo torna-se membro do gênero humano por uma série de objetivações e apropriações de ordem social e histórica. Todavia, há uma atividade humana, uma práxis social que se diferencia substancialmente das outras práxis humanas em razão da sua função social, ou seja, do papel que exerce para a reprodução social, para a continuidade do "mundo dos homens". Esta atividade primária é o trabalho e possui como função social - na análise marxiana - a transformação da natureza para a produção de valores de uso. O trabalho é uma categoria ontológica do ser social, ou seja, para que a humanidade continue a existir é necessário que exista trabalho para transformar a natureza e atender as necessidades humanas. Os atos de trabalho irão dar origem a uma série de outros complexos sociais, como a educação (que é, assim como os demais, um complexo fundado), pois, neste caso, os conhecimentos e habilidades que se originaram pelo trabalho precisam ser transmitidos e apropriados pelos seres humanos.

Entretanto, para podermos afirmar que educação e trabalho possuem funções sociais qualitativamente diferentes - na perspectiva ontológica - é imprescindível entender o que é abordagem histórico-ontológica. Isso implica em levar em consideração o ato fundante que é o trabalho articulado com os demais complexos sociais num sentido de dependência ontológica dos demais complexos para com o trabalho. Também é preciso considerar que tais complexos (no caso em análise a educação) possui uma autonomia relativa, isto é, se desenvolvem mediados por teleologias secundárias num processo complexo de desenvolvimento do ser social que, todavia, não os separa em absoluto da 
objetividade primária fundante. Desse modo, a fim de nos afastar de qualquer crítica quanto a um determinismo mecanicista, também é preciso nos atentar para a relação de determinação recíproca que o complexo educativo possui com o trabalho, isto é, as múltiplas influências que ocorrem na interferência dos homens com a natureza e deles entre si. Aliás, o próprio Lukács entende a relação recíproca entre tais complexos, inclusive, ao afirmar que: "O fator subjetivo, resultante da reação humana e tais tendências de movimento, conserva-se sempre, em muitos campos, como um fator por vezes modificador e, por vezes, até mesmo decisivo" (LUKÁCS, 1978, p.13).

Tonet (2007) nos alerta que é de suma relevância, em todos estes aspectos, considerarmos a origem, a natureza e a função social que determinada atividade humana exerce para a reprodução social. Por função social devemos entender "a função que determinada atividade humana, determinada dimensão social tem na reprodução social" (TONET, 2007, p. 05). E a origem, por sua vez, não se trata de uma busca pelo exato surgimento cronológico de alguma atividade humana, mas sim, a origem históricaontológica, isto é: a origem de um determinado complexo social analisado na sua relação com os atos de trabalho e com a totalidade social.

O trabalho é um ato de pôr consciente e, portanto, pressupõe um conhecimento concreto, ainda que jamais perfeito, de determinadas finalidades e de determinados meios. Vimos que o desenvolvimento, 0 aperfeiçoamento do trabalho é uma de suas características ontológicas; disso resulta que, ao se constituir, o trabalho chama à vida, produtos sociais de ordem mais elevada. Talvez a mais importante dessas diferenciações seja a crescente autonomização das atividades preparatórias, ou seja, a separação - sempre relativa - que, no próprio trabalho concreto, tem lugar entre o conhecimento, por um lado, e, por outro, as finalidades e os meios. A matemática, a geometria, a física, a química etc., eram originariamente partes, momentos desse processo preparatório do trabalho. Pouco a pouco, elas cresceram até se tornarem campos autônomos de conhecimento, sem porém perderem inteiramente essa respectiva função originária. Quanto mais universais e autônomas se tornam essas ciências, tanto mais universal e perfeito torna-se por sua vez o trabalho; quanto mais elas crescem, se intensificam etc., tanto mais se torna a influência dos conhecimentos 
Pesquisa em Foco ISSN (2176-0136)

http://ppg.revistas.uema.br/index.php/PESQUISA EM FOCO

São Luís, v. 22, n. 2, Jul./Dez. 2017 assim obtidos sobre as finalidades e os meios de efetivação do trabalho. (LUKÁCS, 1978, p. 09-10, grifos nossos)

O recurso à citação direta do texto de Lukács (1978) é preciso, pois a partir dele e de outros momentos que integram sua Ontologia do ser social podemos perceber a autonomia relativa dos complexos sociais com relação ao momento fundante. $\mathrm{O}$ fato do trabalho "chamar à vida produtos sociais de ordem mais elevada" - faz com que a educação, por exemplo, se insira neste aspecto - ou seja, isto não quer dizer que tais complexos se separam de modo absoluto, mas sim, "sempre relativa", possibilitando a explicitação tanto da dependência ontológica, quanto da autonomia relativa de que Tonet (2005) nos esclarece. Já a determinação recíproca está presente no fato de que o trabalho ao "chamar à vida" novos complexos sociais, passa a influenciar o desenvolvimento desses complexos e, também, por eles passa a ser influenciado.

Toda essa reflexão nos comprova a impossibilidade de argumentar sobre educação e trabalho como idênticos, quando em verdade se tratam de complexos ontologicamente distintos e com funções sociais igualmente distintas no processo de reprodução social do ponto de vista ontológico, do ponto de vista do próprio desenvolvimento concreto do ser social. O processo de trabalho no tornar-se homem do homem, ou seja, no salto ontológico do ser natural ao ser social (que, todavia, não anula em absoluto o caráter biológico presente na constituição humana) já consubstancia pores teleológicos com finalidades diversas ${ }^{2}$ :

Digna de nota, para nós, é aqui a manifestação de uma nova forma de posição teleológica; ou seja, aqui não se trata de elaborar um fragmento da natureza de acordo com finalidades humanas, mas ao contrário um homem (ou vários homens) é induzido a realizar algumas posições teleológicas segundo um modo pré-determinado. Já que um determinado trabalho (por mais que possa ser diferenciada a divisão do

\footnotetext{
${ }^{2}$ O próprio Marx inicia no Livro I, Tomo I de "O Capital" uma discussão ontológica do trabalho, enquanto "condição eterna" da humanidade e presente em todas as formações sociais específicas e apenas posteriormente passa a tratar do trabalho no capitalismo: trabalho abstrato, trabalho produtivo etc.
} 
trabalho que o caracteriza) pode ter apenas uma única finalidade principal unitária, torna-se necessário encontrar meios que garantam essa unitariedade finalística na preparação e na execução do trabalho. Por isso, essas novas posições teleológicas devem entrar em ação no mesmo momento em que surge a divisão do trabalho; e continuam a ser, mesmo posteriormente, um meio indispensável em todo trabalho que se funda sobre a divisão do trabalho. Com a diferenciação social de nível superior, com o nascimento das classes sociais com interesses antagônicos, esse tipo de posição teleológica torna-se a base espiritualestruturante do que o marxismo chama de ideologia. Ou seja: nos conflitos suscitados pelas contradições das modalidades de produção mais desenvolvidas, a ideologia produz as formas através das quais os homens tornam-se conscientes desses conflitos e neles se inserem mediante a luta. (LUKÁCS, 1978, p. 10-11)

Novamente o recurso à citação direta de Lukács (1978) é de suma relevância em compreendermos de modo mais profundo a inviabilidade ontológica em assimilar educação e trabalho como complexos idênticos. O filósofo húngaro nos explica que com o desenvolvimento do processo de trabalho surge a "manifestação de uma nova forma de posição teleológica" que ao contrário de "elaborar um fragmento da natureza de acordo com finalidades humanas" (ato típico do trabalho), encontra respaldo no intuito de induzir "um homem" ou "vários homens" a "realizar posições teleológicas de um modo prédeterminado", ou seja, estamos falando de posições teleológicas secundárias. Tais posições teleológicas atuam na relação dos homens entre si e não do intercâmbio orgânico do homem com a natureza, como é o caso do trabalho em que estão presentes posições teleológicas primárias. Entretanto, tal entendimento não quer dizer que essas posições teleológicas secundárias não tenham importância, pois, ao contrário, elas se conformam em "um meio indispensável em todo trabalho".

O trabalho, portanto, sempre envolve uma prévia ideação ou teleologia, isto é "a construção, na consciência, do resultado provável de uma determinada ação" e, assim, ele pode ser compreendido como um processo "composto pela prévia ideação e pela objetivação", resultando "na transformação da realidade e, ao mesmo tempo, do indivíduo e sociedade envolvidos" (LESSA, 1999, p. 03). 


\section{Pesquisa em Foco ISSN (2176-0136)}

http://ppg.revistas.uema.br/index.php/PESQUISA EM FOCO

São Luís, v. 22, n. 2, Jul./Dez. 2017

Também é preciso compreender que os atos de trabalho ao instaurarem uma causalidade posta (ao colocarem na realidade objetiva uma "lógica" oriunda da ação humana e não meramente da natureza) abrem um campo de possibilidades maior do que o anterior e, ao mesmo tempo, imbuído de certas limitações. Vejamos um exemplo prático: a totalidade social feudal, fundada no trabalho servil, impunha obstáculos à plena expansão e desenvolvimento do capital. Apenas com o capitalismo, fundado no trabalho assalariado/abstrato, é possível o capital se desenvolver e "dominar tudo" (MARX, 2008). Isto acontece porque o campo de possibilidades reais que o trabalho assalariado/abstrato instaura é superior e mais amplo que o campo de possibilidades oriundo do trabalho servil. No feudalismo, por exemplo, era impossível que todas as atividades tivessem como objetivo a produção de mais-valia, pois apenas o trabalho assalariado "coloca" esta possibilidade.

A análise da centralidade ontológica do trabalho nos permite, por isso mesmo, a correta apreensão da relação entre subjetividade e objetividade. A prévia-ideação de construir uma lança para abater (teleologia) um determinado animal, por exemplo, está vinculada às possibilidades concretas oferecidas pela realidade objetiva. Em razão disso que Marx pôde afirmar que: “O modo de produção da vida material condiciona o processo de vida social, política e intelectual. Não é a consciência dos homens que determina o seu ser; ao contrário, é o seu ser social que determina sua consciência" (MARX, 2008, P. 47).

Este raciocínio também é importante em ser refletido no tocante à educação, pois em seu sentido amplo (ontológico) ela visa capacitar os homens a "reagir adequadamente aos acontecimentos e às situações novas e imprevisíveis que vierem a ocorrer depois em sua vida" (LUKÁCS, 2013, p. 130). Dessa forma, a educação cumpre a função social de transmissão e apropriação dos conhecimentos, habilidades e comportamentos desenvolvidos pelos homens histórica e socialmente.

Todavia, estes conhecimentos, habilidades e comportamentos só se originaram a partir daquela atividade sensível humana que é o trabalho. Não poderia existir o complexo 
da educação se não fosse o trabalho (a dependência ontológica que explicitamos anteriormente). Como todo modo de produção é fundado num tipo determinado de trabalho, toda totalidade social se altera, inclusive a educação, no sentido de que ela - em seu conjunto - irá se orientar por aquele tipo determinado de trabalho. Importante afirmar que a totalidade social engloba o "conjunto de todas as relações sociais que sintetizam uma dada formação social" e, neste sentido, ela é uma "expressão do desenvolvimento histórico passado" e, também, o "campo de possibilidade e desafios para o desenvolvimento futuro". (LESSA, 1999, p. 08).

Como o trabalho alienado é um fato comum às sociedades de classe, a orientação geral dominante da educação será para atender aos interesses das classes dominantes. 0 capitalismo é fundado com base no trabalho abstrato/assalariado e, em função disto, a educação também irá ser norteada para atender a manutenção deste tipo de sociabilidade.

O que estamos afirmando é que com a entrada em cena da propriedade privada (aqui entendida como a relação social pela qual uma classe - dominante - se apropria do fruto do trabalho alheio), da sociedade de classes, do Estado e da exploração do homem pelo homem; a educação sofre interferência dessas relações sociais alienantes. Isto, todavia, não quer dizer que a sua função social de transmissão e apropriação do patrimônio material e espiritual amealhado pela humanidade tenha sido descartada, mas sim, que não se trata de todo "patrimônio material e espiritual" que será transmitido e apropriado, porém apenas aquele conjunto de conhecimentos e habilidades que possibilitem a manutenção daquela determinada forma de sociabilidade existente e que se oriente pela forma concreta de trabalho em cada caso analisado. Essa dinâmica também se faz presente no modo de produção capitalista e sobre isso que trataremos no item a seguir.

\section{MODO DE PRODUÇÃO CAPITALISTA: SUBORDINAÇÃO ESTRUTURAL DO TRABALHO AO CAPITAL}

Pesquisa em Foco, São Luís, vol. 22, n. 2, p. 31-62. Jul./Dez. 2017 
Pesquisa em Foco ISSN (2176-0136)

http://ppg.revistas.uema.br/index.php/PESQUISA EM FOCO

São Luís, v. 22, n. 2, Jul./Dez. 2017

O modo de produção capitalista por meio de um longo processo desenvolveu uma série de rupturas com o poder político (Estado Absolutista) e o intercâmbio material do feudalismo (trabalho servil). O capital encontra sua forma mais plena de desenvolvimento e expansão no capitalismo, se emancipando das amarras e limitações que o modo de produção servil lhe impunha, realizando sua emancipação política. O trabalho continua com a função social de transformação da natureza para o atendimento das necessidades humanas e a educação também continua com a função social de transmissão e apropriação do patrimônio histórico-social construído pela humanidade. Entretanto, com o capitalismo, as necessidades a serem atendidas pelo trabalho e os conhecimentos a serem transmitidos e apropriados pela educação, respectivamente, serão para atender aos interesses da reprodução do capital e não dos seres humanos.

É neste sentido que é preciso entender o fato de que toda totalidade social está fundada num determinado tipo de trabalho que orienta todos os demais complexos sociais (educação, filosofia, arte, ciência, religião, etc.). O trabalho escravo fundava o modo de produção escravista, o trabalho servil fundava a sociedade feudal e o trabalho assalariado/abstrato funda a sociedade burguesa (LESSA e TONET, 2012). Houve um avanço com o capitalismo, um progresso inegável na história da humanidade. O trabalho assalariado proporciona as bases que permitirão promover a cidadania moderna, para além dos entraves políticos, religiosos e aristocráticos inerentes ao modo de produção feudal.

Todavia, no capitalismo há a necessidade das pessoas serem livres para poder vender ou comprar a força de trabalho e, assim: "o mercado, e não mais o Estado, passa a ser o organizador da produção na vida cotidiana" e "o mercado nada mais é que a expressão cotidiana do capital" (LESSA e TONET, 2012, p. 47). O mercado se emancipa da tutela do Estado - emancipação política - e a violência não pode ser mais uma consequência direta da ação de um soberano, por exemplo, mas sim junto com uma 
justificação ideológica para que o Estado "vele" seu conteúdo de classe e se apresente como "neutro" frente aos conflitos. Podemos, dessa forma, compreender que a democracia e a cidadania possuem sua origem na emancipação política do capital. Perante o Estado, capitalistas e trabalhadores são cidadãos iguais, contudo, esta igualdade formal possui como base uma desigualdade real e, com efeito, "na medida em que o Estado ignora as reais desigualdades entre os indivíduos, ele na verdade permite ao capitalista a maior liberdade para explorar os trabalhadores e proletários" (LESSA e TONET, 2012, p. 48). Dessa forma, o capital só consegue se reproduzir e ampliar quanto mais subordina o trabalho e quanto menos o Estado interfira na economia. Com a quebra do Estado absolutista pelas revoluções burguesas, "o Estado agora reconhece os direitos individuais de seus cidadãos (acima de tudo, o direito à propriedade) e deles requer alguns deveres", portanto, "é o reino da cidadania e das liberdades democráticas", ou seja, "é o Estado democrático" (LESSA e TONET, 2012, p. 49).

Precisamos realizar esta reflexão com relação à emancipação política para compreender a sua limitação característica e, com isso, explicitar a vinculação orgânica da cidadania moderna com desigualdade real do modo de produção capitalista. E no interior desta forma de sociabilidade é fundamental notar que: “O capital é a potência econômica da sociedade burguesa, que domina tudo" (MARX, 2008, p. 267, grifo nossos). Se o capital "domina tudo" no âmbito da sociedade capitalista, não é de se espantar que a educação também seja impactada. Vamos analisar o caso do trabalho para entender melhor essa questão: o trabalho possui como função social em sentido amplo realizar o intercâmbio orgânico do homem com a natureza para a obtenção dos valores de uso. Todavia, no capitalismo, o trabalho do proletário não serve apenas para produzir valores de uso, mas para produzir mais-valia, ou seja, para produzir trabalho não pago pelo capitalista e, com isso, permitir a acumulação e expansão do próprio capital.

A sociedade capitalista, portanto, será aquela "cuja reprodução social é dominada pela expansão do capital" e esta expansão deve ser entendida tanto no sentido de riqueza acumulada quanto em termos geográfico-territoriais, pois "o capital termina por se tornar

Pesquisa em Foco, São Luís, vol. 22, n. 2, p. 31-62. Jul./Dez. 2017 


\section{Pesquisa em Foco ISSN (2176-0136)}

http://ppg.revistas.uema.br/index.php/PESQUISA EM FOCO

São Luís, v. 22, n. 2, Jul./Dez. 2017

a forma básica da relação social em todo o planeta com o surgimento e desenvolvimento do mercado mundial” (LESSA, 1999, p. 13). Já o capital - isto é sempre importante lembrar - é uma relação social, fundamentalmente caracterizada pela "expropriação da riqueza produzida pelos trabalhadores dando origem a uma forma de propriedade privada que se distingue das formas anteriores pela sua necessidade intrínseca de expansão" e, deste modo, "ao capital é impossível qualquer reprodução que não seja a sua reprodução ampliada" (LESSA, 1999, p. 13)

Um exemplo real e concreto: sabe-se - há algum tempo - que transgênicos e agrotóxicos causam câncer. Contudo, dados da Agência Nacional de Vigilância Sanitária ANVISA - e do Observatório da Indústria dos Agrotóxicos da UFPR mostram que o brasileiro, em média, consome 5,2 litros de agrotóxicos por ano. Apesar deste panorama, o Prêmio Mundial da Alimentação em 2013, reconhecido como uma espécie de Nobel da Agricultura foi concedido para indústrias que desenvolvem transgênicos como a Robert Fraley da Monsanto e a Mary-Dell Chilton pertencente à Syngenta. O mercado de agrotóxicos é monopolizado pelas empresas: Basf, Monsanto, Bayer, Syngenta, Dow e Dupont que, em 2010, obtiveram 67\% de participação no mercado mundial de agrotóxicos. Ainda em 2010, o lucro dessas multinacionais foi de 7,3 bilhões de dólares e alcançando em 2011 o patamar de 8,2 bilhões de dólares. As empresas se apropriam do lucro e o Brasil fica com o custo social, ambiental e a contaminação (FOLGADO, 2014). Não é por acaso que a cada ano, 03 milhões de pessoas são intoxicadas com os agrotóxicos e mais de 220 mil chegam a morrer, o que corresponde a 660 mortes por dia, 25 mortes por hora (GÓMEZ, 2012).

Disto, podemos perceber claramente que no capitalismo o que importa não é a produção de alimentos que sejam saudáveis para atender as necessidades de alimentação de todos os seres humanos, mas sim, se produz alimentos da forma que o capital possa se reproduzir, da maneira como o capital determina que seja, com a supremacia absoluta de se expandir e extrair mais-valia do trabalho do proletário rural. O mesmo se pode dizer 
com relação à educação. Não importa ao capital que os indivíduos se apropriem de toda cultura humana - em sentido amplo - construída histórica e socialmente pela humanidade. Interessa ao capital que os indivíduos possam se apropriar dos conhecimentos, habilidades, comportamentos e visões de mundo que possibilitem garantir a sua própria reprodução de modo cada vez mais intenso e extenso. O próprio Lukács reconhece isso ao afirmar:

Se hoje a escola é obrigatória e universal nos países civilizados e as crianças não trabalham por um período relativamente longo, então também esse período de tempo liberado para a educação é um produto do desenvolvimento industrial. Toda sociedade reivindica certa quantidade de conhecimentos, habilidades, comportamentos etc. de seus membros; o conteúdo, o método, a duração etc. da educação no sentido mais estrito são as consequências das carências sociais daí surgidas. (LUKÁCS, 2013, p. 130, grifos nossos)

Basta pensar essa elaboração no que diz respeito à educação na atualidade: os conteúdos, as formas, os programas, as avaliações, as políticas públicas etc. são criados de modo a permitir plenamente os homens tornarem-se membros do gênero humano? Ou em linhas gerais - cada vez mais se forma mão-de-obra qualificada para atender as demandas do capital? Outro exemplo disso que estamos argumentando é a escola do Instituto Germinari ${ }^{3}$, que se propõe o desafio de - preparar jovens para o ambiente profissional com conteúdos dirigidos para a administração e gestão de negócios. Este instituto surgiu em 2009 e faz parte da J \& F Investimentos, que possui articulações com empresas como: JBS (uma das maiores processadoras de proteína animal do mundo); Vigor (atua na área de produtos lácteos); Flora (empresa de cosméticos e limpeza); Eldorado (atua na área da celulose); Banco Original; Oklahoma e Floresta Agropecuária (setor de agronegócio) e Canal Rural. A escola localiza-se no município de São Paulo - SP,

3 Informações mais profundas e todas as citações extraídas se encontram disponíveis em: < http://www.escolagerminare.org.br/instituto-jbs/index.php> http://canalrural.ruralbr.com.br/noticia/2013/07/canal-rural-apoia-a-educacao-empreendedora-no-brasilatraves-do-instituto-germinare-4202076.html> Último acesso em: Dez. 2013 


\section{Pesquisa em Foco ISSN (2176-0136)}

http://ppg.revistas.uema.br/index.php/PESQUISA EM FOCO

São Luís, v. 22, n. 2, Jul./Dez. 2017

em terreno de uma das empresas da J \& F Investimentos, com o "compromisso de oferecer alta qualidade de ensino para jovens potenciais com o propósito de formar administradores de empresas e gestores de negócios, que serão líderes do futuro". Esta escola oferece instrução gratuita no Ensino Fundamental II e Ensino Médio com a meta de: "disseminar uma proposta educacional que reconheça e abra possibilidades para jovens de alto potencial que, de outra forma, não teriam condições de utilizar seus talentos para projetos mais ousados de vida", sendo que "os alunos realizam, em caráter permanente, projetos de empreendedorismo, visitas à Bolsa de Valores, e também a ambientes produtivos e corporativos, além de encontros com especialistas".

A desigualdade real que funda o capitalismo e que emana do trabalho assalariado/abstrato é irreformável, porém não quer dizer que não seja superável. Vimos como que, por meio do ato de compra e venda da força de trabalho, a extração de maisvalia permite o capital se acumular e expandir e esta é uma dinâmica extremamente necessária para que este sistema continue a se reproduzir. Não existe capital parado, estático. A relação social que o capital promove é cada vez mais destrutiva (MÉSZÁROS, 2002) com relação às necessidades humanas, por isso que a igualdade não conseguirá na sociabilidade burguesa - deixar de ser uma igualdade formal, pois querer uma igualdade substantiva, no sentido de acabar com as desigualdades sociais e a exploração do homem pelo homem, só é possível para além do capital, isto é: numa sociedade comunista!

É preciso notar que o "segredo" da produção capitalista reside no fato de que o capitalista "paga ao trabalhador o equivalente ao valor de troca da sua força de trabalho e não o valor criado por ela na sua utilização (uso) - e este último é maior que o primeiro" (PAULO NETTO e BRAZ, 2012, p. 100). As relações de produção capitalista geram, portanto, um enorme impacto sobre a classe trabalhadora não apenas no que diz respeito à questão do desemprego, mas ainda, no que se refere aos processos de pauperização. Ao contrário do que os defensores do capital alegam, o desemprego não é uma decorrência 
"natural" do desenvolvimento das forças produtivas, mas sim do "desenvolvimento das forças produtivas sob as relações sociais de produção capitalistas" (PAULO NETTO e BRAZ, 2012, p. 134). Já os processos de pauperização são uma decorrência do próprio movimento de expansão, acumulação e concentração do capital.

Neste sentido, o trabalho produtivo no capitalismo é mais amplo e mais estreito. É mais amplo, pois inclui outras atividades humanas que não apenas que transformam a natureza (quem realiza esta função no capitalismo são os proletários, assim como no feudalismo eram os servos e no escravismo eram os escravos). Também é, ao mesmo tempo, mais estreito que o trabalho em seu sentido ontológico, pois só produz mais-valia (LESSA, 2007, p. 221). Dessa forma, todos os complexos sociais serão "arrastados" para o enorme abismo egocêntrico do capital. Se estivermos analisando a educação inserida no processo histórico real, interagindo numa totalidade social e matrizada pelo trabalho abstrato/assalariado (no caso do capitalismo), verificaremos que por mais que queiramos com todas as nossas forças e desejos, ela sempre irá atender em seu conjunto aos interesses e demandas do capital. Ignorar este fato é abandonar uma análise baseada numa perspectiva ontológica marxiana (ou seja, que analisa a realidade como ela é e não como nós imaginamos que ela seja!) e nadar "de braçada" no idealismo o que, fatalmente, nos levará a posturas reformistas e politicistas. Entretanto, isto não quer dizer que não seja possível o desenvolvimento de atividades educativas emancipadoras, ou seja, atividades que estejam orientadas pela emancipação humana e não pelas limitações intrínsecas e irreformáveis da emancipação política.

\section{ATIVIDADES EDUCATIVAS EMANCIPADORAS}

É imprescindível ter em mente as reflexões anteriores para entendermos o correto equacionamento da relação entre o complexo da educação e o trabalho enquanto categoria fundante do ser social. Além disso, tendo tais elaborações por base, fora possível compreender - mesmo que brevemente - a lógica incorrigível e estruturalmente 


\section{Pesquisa em Foco ISSN (2176-0136)}

http://ppg.revistas.uema.br/index.php/PESQUISA EM FOCO

São Luís, v. 22, n. 2, Jul./Dez. 2017

desigual do modo de produção capitalista e como isso impacta também o trabalho e a educação. Agora, enfim, já temos os elementos basilares suficientes para compreender o conceito de "atividades educativas emancipadoras".

Antes de avançar é preciso sinalizar que se buscarmos bases, programas, conteúdos, currículos e "uma didática" das atividades de cunho emancipador como debatida por Tonet, a investigação já está - desde o início - fadada ao fracasso. Não há uma "receita de bolo"; "palavra mágica" ou "didática" presente na obra deste autor no que concerne ao debate sobre o complexo da educação. Há, todavia, uma análise crítica e revolucionária de cunho histórico-ontológico (claramente a partir da ontologia marxiana), isto é, uma análise da educação em meio a um "complexo de complexos" no ser social que se articula a esta totalidade, tendo no trabalho sua categoria fundante. Podemos dizer que em tal perspectiva ao analisar a educação - ou qualquer outra práxis humana - há a consideração da origem, da natureza e da função social que determinada práxis cumpre no processo de reprodução do ser social como já fora explicada em diversos momentos por Tonet, seguindo as pistas deixadas por Lukács em sua Ontologia.

Não concordamos com o posicionamento de que nada é possível (no sentido da luta revolucionária) ser feito em sala de aula - seja na universidade, seja em uma escola. Todavia, também não temos a ilusão de "querer pensar uma educação emancipadora (conteúdos, métodos, técnicas, currículos, programas, formas de avaliação, etc.) como um conjunto sistematizado que possa se transformar em uma política educacional" (TONET, 2012, p. 38). Este modo de encarar as coisas não tem nada de derrotismo ou reprodutivismo mecanicista.

A educação influencia e é influenciada pelo trabalho em seu aspecto estrito em determinada formação social e é ele quem irá determinar "certa quantidade de conhecimentos, habilidades, comportamentos etc. de seus membros". Tal raciocínio se dá a partir de uma abordagem tanto histórico-ontológica quanto no que se refere à prioridade ontológica da objetividade sobre a subjetividade. Não importa o quanto 
queiramos e/ou desejamos uma escola ou universidade "justa", "emancipadora", "igualitária", "popular" etc., pois, é preciso apreender do processo histórico que tais desejos e vontades não podem se efetivar em sua totalidade no âmbito da sociabilidade burguesa de domínio do capital. Daí também o fato de entender que: "uma reformulação significativa da educação é inconcebível sem a correspondente transformação do quadro social no qual as práticas educacionais da sociedade devem cumprir as suas vitais e historicamente importantes funções de mudança" (MÉSZÁROS, 2005, p. 25). Ou seja, é impossível efetivamente obtermos uma educação "emancipadora e crítica" sem rompermos com a totalidade do sistema sociometabólico do capital que estruturalmente coloca seus imperativos de reprodução acima dos interesses e necessidades humanas. Deste modo, antes de querer a revolução "por dentro da escola ou da universidade pública", é fundamental que façamos a crítica histórica-ontológica destas instituições e do Estado e que possamos entender qual a função social da educação em sentido ontológico (sentido amplo) e suas particularidades (sentido estrito) no âmbito da sociedade burguesa.

Tais reflexões também são importantes para não colocar sobre os "ombros" do campo educacional uma responsabilidade que lhe é inviável como, por exemplo, os rótulos de "educação emancipadora"; "educação para criar cidadãos críticos e transformadores" etc. Para isso é fundamental entender a diferença qualitativa entre a emancipação política e a emancipação humana. Por emancipação humana entendemos:

[...] uma forma de sociabilidade, situada para além do capital, na qual os homens serão plenamente livres, isto é, na qual eles controlarão, de maneira livre, consciente, coletiva e universal o processo de produção da riqueza material (o processo de trabalho sob a forma de trabalho associado) e, a partir disto, o conjunto da vida social (TONET, 2014, p. 02, grifos nossos)

Já a emancipação política, como fora discutida no item anterior, se relaciona à origem da cidadania moderna, ou seja, significa os processos políticos e culturais necessários para a superação do Estado Absolutista e a constituição do Estado moderno, 


\section{Pesquisa em Foco ISSN (2176-0136)}

http://ppg.revistas.uema.br/index.php/PESQUISA EM FOCO

São Luís, v. 22, n. 2, Jul./Dez. 2017

com a consequente superação do trabalho servil para a consolidação do trabalho assalariado/abstrato. Por isso a emancipação política é visceralmente limitada a esta forma de sociabilidade burguesa e a emancipação humana aponta necessariamente para além do capital.

Em razão disto que a educação em seu conjunto, nesta sociedade, não conseguirá estar voltada para o objetivo do socialismo/emancipação humana. Com isso, concordamos com Tonet (2012) na impossibilidade da "educação emancipadora", mas sim na realização de "atividades educativas emancipadoras". Essa interpretação em nada possui de pessimismo ou de um pensamento derrotista. Ao contrário, é a partir das possibilidades históricas e concretas que pensamos na contribuição de iniciativas, problematizações e intervenções que defendam a emancipação humana e, com isso, permitam contribuir com a mobilização da classe trabalhadora rumo à superação do modo de produção capitalista.

Neste ponto vale a pena uma reflexão: porque "atividades educativas emancipadoras" e não uma "educação revolucionária"? É muito comum esbarrarmos em compreensões, no campo marxista, que alegam o fato de que no capitalismo há a educação da classe dominante e que - "dialeticamente" - também existiria uma educação da classe trabalhadora sendo que esta sim deve ser valorizada na luta contra aquela. Contudo, é preciso relembrar aquela relação entre objetividade e subjetividade que apontamos anteriormente no item sobre a relação entre a educação e o trabalho. Os seres humanos por meio dos atos de trabalho instauram uma causalidade posta, ou seja, uma "lógica" eminentemente histórica e social e não meramente dada pela natureza. Esta causalidade posta permite surgir o campo de possibilidades reais e concretas que uma totalidade social pode oferecer a partir do determinado tipo de trabalho que a funda. Se analisarmos o modo de produção capitalista, fundado no trabalho assalariado/abstrato, verificaremos que este tipo de trabalho é estruturalmente desigual. Dessa forma, o campo de possibilidades que esta totalidade social no capitalismo coloca, faz com que seja impossível a efetivação do complexo social da educação - em seu conjunto - ser 
"emancipador". A educação é fundada ontologicamente pelo trabalho e não o contrário. Por isso, o que a totalidade social capitalista coloca como possibilidade real é o desenvolvimento de atividades educativas emancipadoras.

Se afirmarmos - na esteira de Marx e Lukács - que o trabalho é a categoria fundante do ser social e que toda formação social específica possui um determinado tipo de trabalho que a funda, como podemos então argumentar ser possível uma educação em seu conjunto que seja "revolucionária e emancipadora" sem rompermos com o trabalho assalariado/abstrato que funda o modo de produção capitalista? É aqui que ganha expressividade lúcida e radical o conceito de "atividades de cunho emancipador", pois enquanto não caminharmos de modo cada vez mais acentuado na luta socialista, querer que o complexo social da educação se altere radicalmente sem nos preocuparmos com mais nada é o mesmo que querer que os capitalistas se humanizem e passem a dividir seus lucros com todos.

Essa compreensão é possível a partir da consideração em sentido marxiano de que os indivíduos não precedem, ontologicamente, a sociedade. A natureza dos indivíduos possui íntima conexão com as relações sociais. É falso, deste modo, afirmar que os homens são "naturalmente egoístas", eles tornam-se egoístas e/ou solidários em função das relações sociais historicamente construídas (TONET, 2012). Assim, é fundamental conhecer as possibilidades, as contradições, limites e desafios que as condições materiais históricas apresentam, pois "propor-se a formar, hoje, o homem integral sem apontar, claramente, a supressão das condições materiais que impedem essa formação é o mesmo que querer construir uma casa sem os alicerces" (TONET, 2012, p.55).

Deste modo, devemos estimular o desenvolvimento de ações/atividades educativas que se preocupem com a emancipação humana. A educação em seu conjunto na sociedade capitalista não poderá dar conta deste desafio, visto que ela é uma mediação em uma sociabilidade de "complexos de complexos" e, com isso, é necessário entender que: “Contribuir para uma educação integral, hoje, só pode ter o significado de formar indivíduos comprometidos - teórica e praticamente - com a construção de uma 


\section{Pesquisa em Foco ISSN (2176-0136)}

http://ppg.revistas.uema.br/index.php/PESQUISA EM FOCO

São Luís, v. 22, n. 2, Jul./Dez. 2017

forma de sociabilidade - o comunismo - em que aquela formação integral possa efetivamente ser realizada" (TONET, 2012, p.83).

Uma orientação revolucionária do conhecimento - tanto para as Ciências Naturais, Exatas ou Humanas e Sociais - aponta para a consideração da concepção de mundo presente na abordagem científica, na transmissão do conhecimento e no ensino. Isso é fundamental de ser debatido já que é a partir da compreensão da natureza, da função social e da origem que podemos afirmar - ao lado de Lessa e Tonet na esteira de Lukács e Marx - que a educação - em sentido ontológico - não é trabalho. Todavia é imprescindível - dada a polêmica que esta afirmação provoca - que não se trata de uma opção subjetiva e de "vontade individual" de um pesquisador considerar que a educação é ou não trabalho. Trata-se, antes de tudo, como temos explicitado, do exame ontológico que cada uma dessas práxis desenvolvem no processo de reprodução do ser social, como já afirmamos. Ou seja, de modo algum implica em valorações moralistas como já argumentamos. Com efeito, é fundamental na promoção de atividades educativas de cunho emancipador um conhecimento de talhe revolucionário sendo aquele que permite compreender o objeto de estudo (tanto natural quanto social) enquanto "um momento do processo de construção da totalidade social” (TONET, 2014, p. 07). Isto também é fundamental, pois:

[...] assim como, no próprio trabalho, o saber real sobre os processos naturais que em cada oportunidade se põem em questão, foi inevitável para poder desenvolver com êxito o intercâmbio orgânico da sociedade com a natureza, do mesmo modo um certo saber sobre o modo pelo qual os homens são feitos, sobre as suas recíprocas relações sociais e pessoais, é aqui indispensável para induzi-los a efetuar as posições teleológicas desejadas. (LUKÁCS, 1978, p. 11)

Ora, não basta que apenas se transmita o conhecimento mais desenvolvido e elaborado pela humanidade. Já vimos que isto é impossível no capitalismo. É substancial que seja, portanto, uma orientação revolucionária do conhecimento para que possam 
induzir os homens a "efetuar as posições teleológicas desejadas" e, nesse horizonte, se trata de uma orientação socialista, em que a atividade educativa esteja efetivamente orientada pela emancipação humana. Como já afirmamos isto não implica em imobilismo ou derrotismo, mas sim na cautela necessária para "limpar o terreno" da educação das perspectivas reformistas e metafísicas. Como Lukács (1978) explicita, assim como é necessário um conhecimento para a efetivação do trabalho (homem-natureza), também é preciso "um certo saber sobre o modo pelo qual os homens são feitos, sobre as suas recíprocas relações sociais e pessoais" para que seja possível "induzi-los a efetuar as posições teleológicas desejadas", isto é: para o desenvolvimento de atividades educativas baseadas em uma perspectiva revolucionária não basta apenas o acesso ao conhecimento elaborado, mas a sua transmissão numa perspectiva crítica e, portanto, pautada na ontologia marxiana, para que possamos contribuir com as possibilidades históricasconcretas de superação do sistema do capital.

Uma orientação revolucionária do conhecimento indispensavelmente deve ser realizada a partir do estudo individual e coletivo da ontologia marxiana. Marx instaurou uma nova ontologia do ser social ao colocar nas mãos dos próprios homens o desenvolvimento do processo histórico e real. Portanto, não partiu de uma "ideia" ou uma "especulação". A análise marxiana parte "da terra", isto é, da realidade produzida pelos próprios homens se relacionando entre si e com a natureza, parte dos homens tal como eles são. A análise da categoria do trabalho, se relacionando com os demais complexos sociais e com o correto equacionamento entre objetividade e subjetividade são aspectos essencialmente radicais da ontologia marxiana e abrem a possibilidade da perspectiva revolucionária. O capitalismo não é visto, nesta "lógica", como a sociabilidade absoluta e intransponível construída pela humanidade, mas sim, como um modo de produção historicamente consolidado pelos próprios homens e que pode ser superado por uma forma de socialidade qualitativamente superior. Em função disto que é de extrema relevância o estudo sobre a ontologia marxiana para uma orientação revolucionária do conhecimento.

Pesquisa em Foco, São Luís, vol. 22, n. 2, p. 31-62. Jul./Dez. 2017 


\section{Pesquisa em Foco ISSN (2176-0136)}

http://ppg.revistas.uema.br/index.php/PESQUISA EM FOCO

São Luís, v. 22, n. 2, Jul./Dez. 2017

Inclusive é preciso ter clareza de que o objetivo de acesso universal a uma educação de alta qualidade "não é alcançável no interior do capitalismo e, nesta situação de crise estrutural, cada vez menos". Educação de qualidade no capitalismo é uma educação que atenda aos interesses de reprodução do capital, já no comunismo a educação possibilitará aos indivíduos terem acesso ao patrimônio material e espiritual acumulado pela humanidade histórica e socialmente. No capitalismo uma "certa universalização quantitativa (também qualitativa)" é exigida, porém com o rebaixamento da qualidade de modo cada vez mais explícito. Assim, para efetivamente resolvermos tal questão é fundamental possamos entender que "a possibilidade do acesso universal a uma educação de alta qualidade só existe numa sociedade comunista" (TONET, 2010, p. 51).

A própria trajetória intelectual de Lukács, por exemplo, é prova da necessidade de uma orientação de cunho revolucionária ao conhecimento e não apenas o acesso ao saber elaborado. O filósofo húngaro teve uma educação de mais alto nível, dispondo de acesso à cultura, à arte, aos filósofos clássicos e modernos, enfim, teve contato e se apropriou do que a humanidade havia desenvolvido de mais elaborado no campo científico, estético e artístico. Isso quer dizer que o filósofo húngaro sempre teve como horizonte o comunismo? Isso quer dizer que ele sempre teve em mente a centralidade ontológica e política do trabalho? Obviamente que não.

Mas a "conversão" de Lukács ao comunismo não é nada misteriosa. Como viu Leandro Konder, "a opção pelo comunismo fora largamente preparada pela constante rebeldia, pelo anseio de soluções radicais, pela apaixonada negação da sociedade burguesa". A recusa do mundo burguês, ponto de partida do jovem Lukács, localiza agora o sujeito social que pode conferir-lhe um sentido positivo: na segura interpretação de Löwy, "em 1918/1919, Lukács encontra no proletariado a força capaz de resolver as antinomias pela destruição da realidade capitalista, a abolição da reificação, a realização de valores autênticos e a fundação de uma nova cultura". (PAULO NETTO, 1983, p. 28, grifos nossos) 
Ao lado dessa "negação da sociedade burguesa" o contato com a obra marxiana é de fulcral e decisiva influência na constituição da reflexão luckásiana como o próprio filósofo comenta:

\begin{abstract}
A relação com Marx é a verdadeira pedra de toque de todo intelectual que leva a sério o esclarecimento da sua própria concepção de mundo e do desenvolvimento social, particularmente a situação atual, a sua inserção nela e seu posicionamento frente a ela. A seriedade, 0 escrúpulo e a profundidade que dedica a este problema indicam se e em que medida o intelectual pretende, conscientemente ou não, furtar-se a uma clara tomada de posição em face das lutas históricas contemporâneas (LUKÁCS, 2008, p. 37, grifos nossos)
\end{abstract}

Esta provocação é necessária para sustentar a necessária orientação de cunho revolucionário ao conhecimento no âmbito de atividades educativas que se norteiem pela emancipação humana. Não basta, pois a transmissão. É preciso ter a clareza de que "não se trata de abrir mão das lutas pelo acesso universal a uma educação de alta qualidade (no sentido revolucionário). Mas, é preciso ter claro que este objetivo não é alcançável no interior do capitalismo e, nesta situação de crise estrutural, cada vez menos" (TONET, 2010 , p. 51). Justamente em função disto, reforçamos a tese da necessidade em realizar "atividades educativas que contribuam para a formação de uma consciência revolucionária" em que a emancipação humana seja o norte e não o "aperfeiçoamento da democracia e da cidadania", já que a "a questão é formar indivíduos que tenham consciência de que a solução para os problemas da humanidade está na superação da propriedade privada e do capital e na construção de uma forma comunista de sociabilidade" (TONET, 2010, p. 51).

Deste modo, concordamos com o autor ao apontar alguns requisitos fundamentais à atividade educativa de caráter emancipador. Em primeiro lugar, há que se pensar no conhecimento, de modo que seja "profundo e sólido" - se quisermos: radical como compreendido pela ontologia marxiana - a respeito do fim que se pretende alcançar, a saber: a emancipação humana, a perspectiva "para além do capital". Neste aspecto é 


\section{Pesquisa em Foco ISSN (2176-0136)}

http://ppg.revistas.uema.br/index.php/PESQUISA EM FOCO

São Luís, v. 22, n. 2, Jul./Dez. 2017

imprescindível a compreensão - materialista e dialética - do processo histórico e social, compreendendo-os enquanto frutos da atividade humana e não de "potências divinas ou naturais" (TONET, 2014).

Um segundo requisito é a necessária apropriação do processo histórico real, tanto em suas "dimensões universais e particulares", pois - mais uma vez - a educação se insere de modo historicamente herdado e em meio à materialidade concreta produzida pelos homens a partir - primordialmente - da forma como organizam o seu intercâmbio com a natureza. Assim, "é preciso, pois, buscar um saber de base ontológica, regido pelo princípio da totalidade e inseparável da afirmação de que o processo de produção material é a matriz ontológica do ser social. Como a perspectiva de um saber de base ontológica é quase que totalmente desconhecida e/ou rejeitada pelo universo intelectual, ela exige um investimento redobrado" (TONET, 2005, p.149). Trata-se de desenvolver atividades que possibilitem o entendimento a respeito das origens e da natureza da sociabilidade capitalista, da reprodução do capital e da crise estrutural atual (TONET, 2014).

Outro requisito igualmente importante se dá em função da compreensão da especificidade da educação, pois não basta "qualquer conceito de educação", pois nem todos são consistentes com a emancipação humana. Isso também implica em compreender os "alicerces" e a natureza da construção de uma sociedade comunista, se esta vier a se constituir. Do mesmo modo que o capitalismo exige a internalização de comportamentos, valores e ideias condizentes e coerentes com sua reprodução, a construção de uma sociedade comunista implica que os indivíduos compreendam a superioridade desta forma de sociabilidade sobre as limitações da sociedade burguesa e isto, por sua vez, "tem que tomar como ponto de partida a categoria do trabalho e compreender como, a partir dela se originam todas as outras dimensões da vida social" (TONET, 2014, p. 10). 
Um quarto aspecto necessário está em dominar os conteúdos próprios de cada área, pois, por exemplo: “O momento predominante - mas não único - que faz de um físico um educador emancipador não está no seu compromisso político, mas no seu domínio do saber e da difusão do conteúdo específico e de um modo que sempre estejam articulados com a prática social" (TONET, 2005, p. 150). Também é preciso compreender a natureza específica da educação e a função social que ela cumpre, em suas possibilidades e seus limites, com intuito de evitar a "supervalorização da educação" em que ela é entendida como capaz de tudo e, também, para evitar a desvalorização desta atividade e, dessa forma, apreender sua "contribuição ativa na luta revolucionária" (TONET, 2014).

Deste modo, um quinto requisito, por sua vez, implica na articulação da práxis educativa com as lutas da classe trabalhadora, sem que isso deixe de prezar pela necessidade de rigor e comprometimento com a tarefa do conhecimento. Em face de toda derrota que o movimento comunista tem sofrido, a estratégia reformista soa a muitos intelectuais e militantes como o "mal menor" e "a ponte" para "pouco a pouco" alcançarmos "vitórias" maiores. Contudo, é imprescindível - se compreendermos efetivamente a necessidade histórica da perspectiva "para além do capital" orientar atividades educativas pela emancipação humana.

Resumindo: atividades educativas emancipadoras - de acordo com Tonet - devem propiciar: 1) o entendimento do desenvolvimento e complexificação do ser social (e dos vários modos de produção) com base na própria atividade humana e não em potências místicas e/ou transcendentais; 2) a compreensão da correta correlação entre trabalho, educação e totalidade social; 3) a precisão na especificidade de cada área a ser transmitida; 4) uma orientação revolucionária do conhecimento no processo de transmissão e 5) o engajamento crítico nas lutas sociais. Estes princípios podem ser praticados em movimentos sociais, sindicais, na universidade pública etc.; contudo, também não temos a ilusão de que tais práticas podem se tornar hegemônicas no âmbito do modo de produção capitalista. O intuito se dá na explicitação do que é possível realizar em um contexto histórico real de profunda crise desta ordem societária burguesa. 


\section{Pesquisa em Foco ISSN (2176-0136)}

http://ppg.revistas.uema.br/index.php/PESQUISA EM FOCO

São Luís, v. 22, n. 2, Jul./Dez. 2017

Assim sendo, reafirmamos o posicionamento de Lukács quando afirma que: "A relação com Marx é a verdadeira pedra de toque de todo intelectual que leva a sério o esclarecimento da sua própria concepção de mundo e do desenvolvimento social" (LUKÁCS, 2008, p. 37). Para que os princípios apontados por Tonet possam ter alguma repercussão por pesquisadores e/ou educadores interessados na luta pelo socialismo e pela emancipação humana, entendemos que é de extrema relevância o contato e estudo rigoroso das contribuições do pensamento de Marx e Engels. Todavia, por uma série de motivos, estas mesmas contribuições foram sendo profundamente deturpadas ao longo do processo histórico. Por isso, defendemos que a tradição marxista conhecida como ontologia marxiana e que encontra em Gyorgy Lukács e István Mészáros seus maiores expoentes (além das obras do próprio Marx), é imprescindível para todos aqueles que querem compreender como o ser social se constituiu, como as alienações do capital proliferam em nosso momento histórico, como se dá o correto relacionamento entre objetividade e subjetividade, enfim, o estudo permanente, coletivo, consciente e imanente do pensamento de Marx, Lukács e Mészáros é, em nosso entender, o primeiro passo indispensável para o desenvolvimento de atividades educativas numa perspectiva revolucionária.

Atividades educativas nesta orientação são muito difíceis de serem efetivadas nas escolas públicas e/ou universidades. Isto não quer dizer que seja impossível, apenas devemos ter a clareza de que elas podem se concretizar nesses espaços sempre de modo muito incipiente e reduzido. Não é difícil compreender a razão deste fato. A hierarquia burocratizante na sala de aula, no funcionamento das instituições educacionais formais, a precarização das condições de realização da própria prática pedagógica, a "selva de pedras" que o capitalismo faz com a educação formal em que cada um luta por seu "lugar ao sol" etc., tudo isto e muito mais fazem com que o desenvolvimento desta proposta de atividades educativas emancipadoras fique - no capitalismo - restrito. Porém, justamente 
esse é o campo de possibilidades construído historicamente pela sociedade burguesa em tempos nossos de crise estrutural do capital.

Sobre este aspecto vale a pena refletir um pouco mais. Não estamos afirmando que a proposta de Tonet não seja possível em ser realizada nas escolas ou universidades públicas, todavia, não é possível admitir que elas sejam amplamente praticadas nesses contextos. Vamos relembrar a função do Estado capitalista, qual seja: “O Estado é burguês precisamente porque é uma mediação para o predomínio do capital sobre a reprodução social" (LESSA, 2007, p. 09). Se nós concordamos com a análise marxiana a respeito do Estado burguês, como é possível acreditar que seja viável - em sua totalidade - a transmissão dos conhecimentos artísticos, filosóficos e culturais mais desenvolvidos pela humanidade em escolas e universidades públicas?

Quem exerce sua prática docente em escolas públicas sabe do que estou falando: avaliações que nada contribuem no sistema de ensino; remunerações baixíssimas; condições físicas escolares extremamente precárias; fraquíssimo (pra não falar quase nenhum) incentivo a que os professores enriqueçam sua formação acadêmica, enfim, vários e vários aspectos extremamente alienantes se fazem presentes na educação formal pública. Nas universidades o mesmo ocorre: aquilo que pode ser considerado como "marxismo" luta por migalhas em projetos e projetos para o desenvolvimento de pesquisas, palestras, minicursos, eventos científicos etc.; entretanto, se trata de uma luta desigual. Um exemplo real e prático: uma pesquisa que procure explicitar a exploração dos proletários rurais em uma usina de processamento de cana-de-açúcar provavelmente terá muitas dificuldades em encontrar financiamento. Em alguns casos, poderá, inclusive, sofrer com ameaças de todo tipo. No entanto, se for uma pesquisa que tente provar como o agronegócio supostamente promove um "desenvolvimento sustentável", certamente, as chances serão bem maiores para encontrar agências de fomento interessadas. Não é necessário escrever mais para compreendermos a quem serve cada uma dessas perspectivas. 


\section{Pesquisa em Foco ISSN (2176-0136)}

http://ppg.revistas.uema.br/index.php/PESQUISA EM FOCO

São Luís, v. 22, n. 2, Jul./Dez. 2017

Em função disso, compreendo que - ao lado da tarefa de estudo sério dos clássicos da história e do marxismo - duas atitudes são absolutamente necessárias para a promoção da proposta elaborada por Tonet (2014). Estas duas atitudes, contudo, não devem ser analisadas como momentos separados. Trata-se da tarefa individual de autoformação, no sentido de que: se estamos realmente preocupados em compreender a sociabilidade regida pelo capital numa perspectiva radical e de ordem revolucionária, nada deve nos afastar de nosso estudo individual, sistematizado e constante. "Apenas" isto já é algo muito difícil de realizar na atualidade em face das múltiplas atividades em que estamos inseridos, das várias alienações que se fazem presentes em nosso cotidiano e que nos impedem de uma compreensão mais profunda sobre diversos temas importantes em nossas vidas, enfim, motivos não faltam para colocar obstáculos ao estudo individual. Entretanto, sem esta prática, muito pouco se pode avançar em termos de atividades educativas emancipadoras, pois assim como a atuação de um educador é fundamental ao processo de transmissão e apropriação do conhecimento, também é fundamental a atuação permanente e sistemática de estudos realizados individualmente.

Outra atitude de igual relevância na busca pela concretização de atividades educativas emancipadoras é a busca contínua por grupos e/ou sujeitos realmente interessados com esta luta. Muitas vezes podemos nos sentir sozinhos, porém é preciso mapear outros indivíduos e/ou coletivos que estejam também comprometidos com a emancipação humana. Sem estas duas atitudes: 1) o estudo individual sistematizado/permanente e 2) a busca coletiva assumidamente socialista; entendo que as possibilidades de concretizar a proposta de Tonet (2014) ficam muito reduzidas.

A necessidade de engajamento prático num coletivo junto a outros indivíduos que lutam pelo socialismo é importante, pois "o poder material tem de ser derrubado pelo poder material, mas a teoria também se torna força material quando se apodera das massas" (MARX, 2010, p.151). Isto significa que não adianta "praticar marxismo em arcondicionado", isto é: sem o nosso esforço individual sistematizado e permanente em 
apreender o movimento próprio do real em uma orientação revolucionária (ontologia marxiana) e sem a perspectiva coletiva de luta concreta e prática, não há possibilidade das elaborações de Tonet se explicitarem em toda sua potencialidade. A classe trabalhadora precisa compreender a constituição do ser social, dos diferentes modos de produção, da lógica do capital e, para isso, necessita de seus próprios espaços e estes apenas surgem com a organização intencional e coletiva dos próprios trabalhadores.

Entendo que estas duas atitudes são importantes de serem praticadas, pois possibilitarão que - em certo grau - tais atividades emancipadoras possam - mesmo que minimamente - se fazerem presentes nas salas de aula formais e em outros contextos. Esse modo de encarar as coisas não exclui o papel do educador que pode ou não também ser um professor, isto é, pode ou não ter passado pelos bancos universitários. Ao defendermos a necessidade do estudo individual sistematizado e permanente, temos a clareza do velho ensinamento marxiano de que "o próprio educador precisa ser educado" (MARX e ENGELS, 2002, p. 100, grifos nossos) e - concomitantemente - ao argumentarmos a necessidade desta empreitada ser necessariamente coletiva, também retomamos o pensamento de Marx e Engels ao defenderem que "o verdadeiro resultado de suas lutas - dos operários - não é o êxito imediato, mas a união cada vez mais ampla dos trabalhadores" (MARX e ENGELS, 2007, p. 38, grifos nossos).

Em função destes dois aspectos é, ainda, importante e necessária a prática militante do educador que se preocupa e luta pelo socialismo. De nada adiante falar do alto, como "gárgulas", olhando a realidade e as lutas de classe com o "ar" de quem paira "acima do bem ou do mal". É preciso que este educador, ou grupo de educadores, lute(m) para que as condições de realização de sua atividade educativa possam se concretizar com a máxima qualidade possível e isso, por sua vez, é irrealizável se não tiver um caráter claramente anticapitalista. Novamente vale a pergunta: é possível conseguirmos uma "educação de qualidade" sem rompermos com o capital? Se respondermos afirmativamente a esta pergunta, das duas uma: ou por "qualidade" entendemos as orientações e requisitos necessários para atender as demandas da sociabilidade burguesa, 


\section{Pesquisa em Foco ISSN (2176-0136)}

http://ppg.revistas.uema.br/index.php/PESQUISA EM FOCO

São Luís, v. 22, n. 2, Jul./Dez. 2017

ou estamos profundamente equivocados. Se defendermos uma educação que possibilite a transmissão e a apropriação do que de mais elevado fora construído e amealhado socialmente pela cultura humana ao logo do processo histórico, então é impossível reconhecer a possibilidade de uma "educação de qualidade" perante toda humanidade no capitalismo. Neste caso, o entendimento profundo e sistematizado desta ordem societária e a necessidade de superá-la, novamente, se fazem mais urgentes do que nunca para aqueles que não querem defender uma perspectiva reformista.

\section{CONSIDERAÇÕES FINAIS}

Não podemos nos iludir com a falácia que tenta nos fazer acreditar serem possíveis grandes transformações educacionais sem que tenhamos substantivas transformações essenciais também na forma como os homens (sociedade) exercem o intercâmbio material com a natureza, ou seja, o trabalho. Perder de vista esta consideração é "caminhar a passos largos" num túnel escuro 4 em que a luz que há no final, ao invés de uma saída, é um trem vindo em nossa direção. Com efeito: “Não pode haver uma solução efetiva para a auto-alienação do trabalho sem que se promova, conscienciosamente, a universalização conjunta do trabalho e da educação" (MÉSZÁROS, 2002, p. 67). Igualmente é importante sinalizar - na esteira de Marx - a impossibilidade de alterações radicais na estrutura da sociedade capitalista por meio do parlamento, do Estado. Justamente o oposto é verdadeiro, ou seja, a classe trabalhadora para efetivar sua tarefa histórica deve superar o Estado, a existência das classes sociais, a exploração do homem pelo homem e a propriedade privada.

Essa tarefa também necessita ser pensada a partir da teoria marxiana em seu aspecto crítico-revolucionário e ontológico, para que enfim, como nos ensinava Lukács

\footnotetext{
${ }^{4}$ Analogia com a frase de Mészáros pronunciada em entrevista à Carta Capital em 24 de junho de 2011, em que o filósofo húngaro se refere ao Presidente Barack Obama. Disponível em: < http://www.cartacapital.com.br/politica/istvan-meszaros-as-contradicoes-dos-nossos-tempos > Último acesso: jun. 2015.
} 
(2013), o homem singular possa apreender sua própria vida como um processo do desenvolvimento do gênero. Esse processo implica a superação do modo de produção capitalista, do trabalho alienado rumo ao socialismo e ao comunismo. Quando este homem singular intenta realizar sua própria conduta como pertencente a esse contexto em movimento, ele, enfim, terá alcançado uma ligação não mais "muda" com a sua própria generidade, pois: "Só quando tiver a intenção de almejar ao menos seriamente uma generidade desse tipo em sua própria vida o homem conseguirá apropriar-se de sua própria elevação acima de seu ser-homem meramente particular - pelo menos como obrigação perante si mesmo" (LUKÁCS, 2013, p.435).

Precisamos lembrar que: 1) a educação (em sentido amplo) enquanto complexo social ontológico do ser social possui a função de transmissão e apropriação do patrimônio cultural (material e espiritual) construído pela humanidade histórica-socialmente; 2) a educação (em sentido restrito) adquire uma peculiaridade dominante com o surgimento das sociedades de classes e da propriedade privada no sentido de que a educação - em seu conjunto - dominante é a educação que atende prioritariamente os interesses das classes dominantes; 3) no aspecto concreto/prático em meio ao momento atual de crise estrutural do capital há a possibilidade de desenvolver atividades educativas de cunho emancipatório, porém deve-se frisar que se tratam de atividades educativas e não a educação em sua totalidade em função do que se sistematizou anteriormente.

Portanto, para que a proposta de Tonet possa se concretizar na realidade objetiva são necessárias aquelas duas atitudes que sinalizamos anteriormente: 1) o estudo individual sistematizado e permanente dos clássicos da histórica e do marxismo e 2) a atuação engajada coletiva com indivíduos e/ou grupos efetivamente preocupados com a luta pela emancipação humana e pelo socialismo. Sem estas práticas muito pouco iremos contribuir com uma perspectiva revolucionária no debate educacional e, com isso, as chances de superestimar ou subestimar inadequadamente a educação aumentarão sensivelmente. 
Pesquisa em Foco ISSN (2176-0136)

http://ppg.revistas.uema.br/index.php/PESQUISA EM FOCO

São Luís, v. 22, n. 2, Jul./Dez. 2017

\section{REFERÊNCIAS}

FOLGADO, C. A. R. Agrotóxicos: Um problema invisibilizado. Movimento dos Pequenos Agricultores -MPA, CLOC/VIA CAMPESINA, Brasília - DF: 2014.

GÓMES, G. C. Los agrotóxicos: el nuevo holocausto invisible. 2012. Disponível em:< http://www.surysur.net/2012/12/los-agrotoxicos-el-nuevo-holocausto-invisible/> Último acesso: Set. 2014.

LESSA, S. O processo de produção/reprodução social: trabalho e sociabilidade.

Capacitação em Serviço Social e Política Social, Módulo 2, pp. 20-33, CEAD-UNB, 1999.

LESSA, S. Trabalho e Proletariado no Capitalismo Contemporâneo. São Paulo: Cortez, 2007.

LESSA, S.; TONET, I. Proletariado e sujeito revolucionário. São Paulo: Instituto Lukács, 2012.

LUKÁCS, G. As Bases Ontológicas do Pensamento e da Atividade do Homem. Temas de Ciências Humanas n. 4. Tr. C.N. Coutinho, São Paulo: Livraria Editora Ciências Humanas, 1978.

LUKÁCS, G. Socialismo e Democratização. Rio de Janeiro: Ed. UFRJ, 2008.

LUKÁCS, G. Para uma ontologia do ser social - II. São Paulo: Boitempo: 2013.

MARX, K.; ENGELS, F. A Ideologia Alemã. São Paulo: Martins Fontes, 2002.

MARX, K.; ENGELS, F. Manifesto Comunista. São Paulo: Boitempo, 2007.

MARX, K. Contribuição à crítica da Economia Política. São Paulo: Expressão Popular, 2008.

MARX, K. Crítica da Filosofia do Direito de Hegel. São Paulo: Boitempo, 2010.

MÉSZÁROS, I. Para além do capital - Rumo a uma teoria da transição. Trad. Paulo Cezar Castanheira e Sérgio Lessa. São Paulo: Boitempo, 2002.

MÉSZÁROS, I. A Educação para além do Capital. São Paulo: Boitempo, 2005.

PAULO NETTO, J. Georg Lukács - O guerreiro sem repouso. São Paulo: Ed. Brasiliense, 1983. 
PAULO NETTO, J.; BRAZ, M. Economia Política: Uma introdução crítica. São Paulo: Cortez, 2012.

TONET, I. Educação, Cidadania e Emancipação Humana. Ijuí: Unijuí, 2005.

TONET, I. Um novo horizonte para a Educação. Texto base conferência pronunciada no I Congresso de Ontologia do Ser Social e Educação, promovido pelo IBILCE - UNESP - São José do Rio Preto em nov/dez 2007. Disponível em: < http://ivotonet.xpg.uol.com.br/ > Último acesso: set. 2015.

TONET, I. Educação e Revolução. Germinal: Marxismo e Educação em Debate, Londrina, v. 2, n. 2, p. 43-53. 2010.

TONET, I. Educação contra o capital. São Paulo: Instituto Lukács, 2012.

TONET, I. Atividades Educativas Emancipadoras. Rev. Práxis Educativa. Vol. 9, n. 1, 2014. 